\title{
La crisis agrícola a fines del siglo XVII e inicios del XVIII en Lima y el centro del Perú: Método historiográfico para el conocimiento del cambio climático en los Andes
}

\section{The agricultural crisis in the late 17th and early 18th centuries in Lima and central Perú: Historiographical method for understanding climate change in the Andes}

\author{
Carlos Carcelén Reluz \\ ccarcelenr@unmsms.edu.pe
}

\author{
Miller Molina Gutiérrez \\ millerhansmg@hotmail.com
}

\author{
Víctor Andrés Medina
}

victore.andresm@gmail.com

Universidad Nacional Mayor de San Marcos

\section{RESUMEN}

Desde fines del siglo XVII hasta fines del XVIII el Perú, en especial el área central, sufrió una serie de transformaciones que afectaron las actividades económicas agrícolas debido al proceso de cambio generado por el fin de la Pequeña Edad de Hielo y el inicio del calentamiento global. En este trabajo partimos desde la perspectiva teórica y metodológica de la Historia del Clima para contribuir y mejorar la interpretación de los mecanismos y las respuestas de las comunidades ante los cambios producidos en este periodo de la historia del Perú. En este texto se presentan los avances en la construcción de series cuantitativas de indicadores como manifestaciones religiosas, precios de productos agrícolas, precios de servicios y mediciones de temperatura, que demuestran los cambios climáticos producidos a lo largo de los siglos XVII y XVIII.

Palabras Clave: Crisis agrícola; Pequeña Edad de Hielo; cambio climático; ENSO; Perú.

\begin{abstract}
From late 17 th century to late 18 th century, Peru, and especially its central area, underwent several transformations that affected agricultural economic activities due to changes caused by the ending of the Little Ice Age and the beginning of global warming. From the theoretical and methodological perspective of the History of Climate, in this article we seek to contribute to interpretations of the mechanisms and responses of communities to the changes occurred in this period of Peru's history. The article presents some of the progress in the construction of series of quantitative indicators such as religious manifestations, prices of agricultural products, prices of services, and temperature measurements, which demonstrate the climate change produced throughout the 17 th and 18 th centuries.
\end{abstract}

Keywords: Agricultural crisis; Little Ice Age; climate change; ENSO; Peru.

(C) Los autores. Este artículo es publicado por ISHRA, Revista del Instituto Seminario de Historia Rural Andina de la Facultad de Ciencias Sociales de la Universidad Nacional Mayor de San Marcos. Este es un artículo de acceso abierto, distribuido bajo los términos de la licencia Creative Commons Atribucion - No Comercia_ Compartir Igual 4.0 Internacional. (http://creativecommons.org/licenses/by-nc-sa/4.0/) que permite el uso no comercial, distribución y reproducción en cualquier medio, siempre que la obra original sea debidamente citada. 


\section{Las coyunturas del clima en las procesiones en rogativa $(1690$ - 1730)}

En este trabajo presentaremos una secuencia de crisis climáticas y su relación con el El Niño/ Oscilación del Sur (ENSO), la cual permitirán entender la articulación ambiental de la economía y establecer, de manera directa, coyunturas de eventos extremos del clima que impactaron en la producción agrícola. Un problema pendiente en la historiografía agraria colonial es que: "las apreciaciones sobre la 'crisis triguera' reposan en fuentes de tipo cualitativo, aisladas y dispersas, que no permiten fechar ni seguir con precisión el desarrollo cronológico del acontecimiento [...] escasean los testimonios directos" (Flores, 1991, p. 25).

\section{Importancia de las rogativas propluvia en la sociedad limeña virreinal}

La recolección de las rogativas en los archivos limeños ha sido empleada en los trabajos de Carcelén $(2007,2009)$ y Bell (2013). La diferencia que sostenemos con estos trabajos es a nivel metodológico. El uso de las rogativas en la presente investigación servirá para formar una intensidad y una clasificación de tipos de rogativa durante este periodo, ya que las 18 rogativas encontradas por Bell (2013) son homogéneas en el ritual, sin diferencia alguna entre ellas. Todas son procesiones de San Marcelo a la Catedral de Lima desde 1600 hasta 1699. Estas plantean que las rogativas fueron una parte del control del espacio hidráulico sobre la atmósfera, en especial, la temporada de garúas entre julio y agosto.

Carcelén (2007) recalca la importancia de las procesiones en rogativas de la sociedad virreinal como medio para la búsqueda de la estabilidad climática ante eventos extremos del clima. Para Vide y Barriendos (1995), las procesiones en rogativa propluvia tenían una influencia alta en identificar cuándo las temporadas agrícolas estaban en crisis por el nivel de severidad en las rogativas, indicando así el grado de sequía, sobretodo en el pan que era el alimento básico.

Como menciona Barriendos, el mecanismo institucional para su realización era:

a. Se produce una variación o anomalía ambiental.

b. El gremio de hortelanos o labradores transmite su inquietud a las autoridades municipales.

c. El gobierno municipal evalúa la situación y toma las determinaciones convenientes, encaminadas a encargar algún tipo de rogativas a la Iglesia.

d. Las autoridades eclesiásticas reciben la orden de realización de una rogativa y realizan las gestiones oportunas para llevarla a cabo, integrar la misma en el calendario de actividades regulares y convocarla al público, si procede (1999).

Vistas las indicaciones anteriores, podemos plantear que las rogativas son un indicador general que nos permitirá establecer ciclos coyunturales y la severidad de las sequías en los productos agropecuarios durante los cuarenta años en los valles de Lima, recalcando que es uno de los varios proxys para entender la crisis de finales del siglo XVII.

\section{Fuentes y metodología para el procesamiento de las rogativas por esterilidad y epidemias en la ciudad de Lima}

La recolección de la información sobre procesiones en rogativas se realizó de los Libros del Cabildo de Lima (LCL) del Archivo Histórico de la Municipalidad (AHML) y en los Libros de Actas Capitulares (LAC) del Archivo del Cabildo Metropolitano de Lima (ACML). En nuestra búsqueda también se halló que las rogativas se registraron en cartas pastorales que se encontraron en la sección Miscelánea Zegarra de la Biblioteca Nacional del Perú (BNP) y en la sección de 
carpetas de cuentas del Cabildo (ACML). El estudio de las rogativas para la historia del clima todavía está en exploración en América Latina; por ello, primero se describirán las rogativas encontradas y sus especificaciones adicionales para diferenciarlas.

\section{Descripción para el procesamiento de las rogativas por eventos extremos en las fuentes}

El 17 de octubre se realizó una procesión en rogativa a San Marcelo porque las "sementeras se perdían por los yelos" (AHML, LCL, n. 32, 1692, fol. 106v). Pero en el Archivo del Cabildo Metropolitano (ACML) se ha encontrado un mismo libramiento de pago que menciona dos procesiones de frutos al señor San Marcelo, que se realizaron el 17 y 25 de octubre de 1692, y una procesión de frutos a la parroquia de San Marcelo el 10 de agosto de 1692 (ACM, serie G, Carpeta de cuentas, segundo libro, s/f).

La segunda procesión del 25 de octubre no menciona si fue en rogativa o esterilidad, pero se constata que el 17 de octubre se realizó una rogativa por perdidas constantes de las "sementeras por los yelos" (AHML, LCL n. 32. 1692, fol., 106v), según la cual los funcionarios del Cabildo Eclesiástico y señores del Cabildo asistieron a la procesión: "tratarían de hacer a venir San Marcelo" (fol. 106v) para bendecir los campos y que la hierofania de este santo se hiciera presente con la fructificación. Por ello, se consideran las dos procesiones del 17 y 25 de octubre de 1692 como una sola rogativa por esterilidad de ida (hacia la Catedral de Lima) y de vuelta (a la parroquia de resguardo), de modo que en los ocho días que van del 17 al 25 lo más probable es que se haya realizado una octava.

En relación a la procesión de frutos del 10 de agosto hacía la parroquia de San Marcelo, hemos considerado en este estudio solo aquellas que se mencionan en rogativa, esterilidad o algún adicional que permita diferenciarla de la denominación procesión de frutos. Por lo tanto, se explicará el por qué, lo que a su vez será de ayuda para futuras exploraciones de fuentes.

Los criterios son los siguientes: todas las divinidades católicas desde San Marcelo hasta Santa Rosa tuvieron una fecha de procesión dentro del marco festivo católico, desde misas, procesiones, vísperas, entre otras. Es común que los libramientos de pago por estas fiestas se hayan nombrado como procesión en su día.

En el caso de San Marcelo, como patrón de los frutos de la ciudad de Lima, su festividad comenzó con la temporada de cosecha, el 18 de enero de cada año (ACM, serie G, Carpeta de cuentas n. 14, s. XVII, s/f), el cual concuerda con la cosecha del trigo en los valles de Lima entre enero y febrero. De acuerdo a Bell (2013: 174), la siembra del trigo comenzaba entre mayo y junio.

El tiempo desde la siembra hasta la cosecha de las variedades tradicionales del trigo duro (triticum turgidum) y del blando o harinero (triticum aestivum), según una investigación de historia experimental realizada por Guzmán et al (2016, p. 5) es de 7 a 8 meses. Según Prieto y Herrera (2001), con cita a De Fina y Ravello (1973), el trigo necesitó precipitaciones abundantes desde el macollaje hasta al espigazón o floración, es decir, entre los meses de agosto y octubre. Durante el invierno las garúas eran importantes para el crecimiento del trigo después de la siembra (Bell, 2013, p. 174).

Se ha encontrado en la carpeta de cuentas de 1688 y 1710 del Cabildo (ACM), procesiones a San Marcelo que se realizaron durante los meses de agosto de cada año bajo la denominación de procesiones de frutos a la parroquia de San Marcelo (anexo: 1). Se considera que esta procesión perteneció a la festividad del régimen agrícola y que correspondió a la temporada de la siembra. 
El 9 de agosto de 1693 se realizó una procesión de rogativa por los frutos a la parroquia de San Marcelo(ACM, serie G, Carpeta de cuentas n. 14, s. XVII, s/f. fechado el 10 de agosto).

El 10 de noviembre de 1694 se realizó un sermón panegírico de rogativa en la Catedral de Lima, por el cual solicitaron el patrocinio de la Virgen María para que la libre de los temblores y sequedad en los campos y serranías (BNP, miscelánea Zegarra, vol. 124, 1694, pp. 20-25). El pago de libramiento, fechado el 10 de agosto de 1695, menciona: "dos procesiones de Nuestra ss.ra del Rosario una de traerla aesta/ dha ss.ta Yglesia para hacerle un Novenario por el buen subceso de/ los frutos a este Reyno y la otra para volverla asu cassa" (ACM, serie G, Carpeta de cuentas, segundo libro, s. XVII, s/f.).

El 9 de agosto de 1695 se realizó una procesión por los frutos desde el arzobispado hasta la parroquia de San Marcelo (ACM, serie G, Carpeta de cuentas n. 16, s. XVIII, s/f.). En el mismo año se han encontrado tres cartas pastorales en rogativa hacia la Catedral de Lima. La primera es del 18 de julio por las procesiones del Santísimo Sacramento y Corpus Christi para evitar la esterilidad de frutos, temblores y el hambre que azotaron al arzobispado (BNP, miscelánea Zegarra, vol. 9, 1695). La segunda, del 5 de agosto de 1695, fue una procesión en rogativa y octavario a Nuestra Señora del Rosario, dirigida hacia la Catedral de Lima para prevenir la esterilidad de frutos y temblores (BNP, miscelánea Zegarra, vol. 9, 1695). La tercera es del 15 de octubre, pidiendo la intercesión de Nuestra del Señora del Rosario frente a la esterilidad de frutos (BNP, miscelánea Zegarra, vol. 9, 1695).

El 7 de octubre de 1703 se firmó una carta pastoral que contenía una revelación de la Virgen María por motivo de la plaga de esterilidad de los frutos (BNP, miscelánea Zegarra, vol. 9, 1703). El 21 de enero de 1704 se realizó una procesión a la parroquia de San Sebastián, en su día, para prevenir la peste (ACM, serie G, Carpeta de cuentas n. 16, s. XVIII, s/f). El 10 de setiembre de 1705 se realizó en dirección a la Catedral de Lima, la procesión en rogativa a Santa Rosa, con reliquias e imágenes de ella para que: "intercediese con su Divina Magestad se dígnase deconcedernos algún alivío en las esterilidades contínuadas, que ha padesído todo este distrito y Reíno" (ACM, serie A, LAC n. 8, 1705. fol. 185v,).

Esta rogativa se registró en los libros de actas capitulares, dado que el asunto fue sobre las contribuciones que hizo el Cabildo y las limosnas sobre el gasto del altar y capilla de Santa Rosa en la iglesia. En el acta de Cabildo de Lima del 22 de octubre de 1705, se declararon los gastos de los obsequios por la rogativa a Santa Rosa (AHML, LCL, n. 33, 1705, fol. 246). En el libramiento del 9 de setiembre de 1705, se registró la fecha de realización: "las dos procesio/nes que sehicieron conlas Reliquias de Nsra Patrona la Ss.ta Rossa de Ss.ta Maria aesta ssta Yglesia y Bolverla asu cassa Savado y Domingo cinco y seis deeste mes" (ACM, serie G, Carpeta de cuentas n. 16, s. XVIII, s/f.).

En el mismo año, el 9 de agosto de 1705, se realizó una procesión por los frutos del arzobispado a la parroquia de San Marcelo (ACM, serie G, Carpeta de cuentas n. 16, s. XVIII, s/f.). El 22 de noviembre de 1708, de la parroquia de San Sebastián a la catedral salió en procesión su imagen principal con San Roque, y se hizo un octavario por epidemia (Polo, 1913). En junio de 1709 se hizo una rogativa a San Roque y un octavario por esterilidad (Carcelén, 2011). El 1 de julio de 1710, la mesa capitular acordó:

se deve azer el novenario q esta/ dispuesto a Nra señora del Rosario q a devenir del combento desanto Domingo y q el ultimo día se aga Procesión General pidiendo asu Divina Mag/ nos conzeda la Sanidad que generalmente se/necesita como 
también el que cesse la general esterilidad que por espasio deveynte años se la experímen/ta (ACM, serie A, LAC n. 10, 1710, fol.105).

El novenario se realizó del 3 al 12 de julio. En el mismo año, el 12 de octubre, se realizó una procesión a Nuestra Patrona Santa Rosa (ACM, serie G, Carpeta de cuentas n. 16, s. XVIII, s/f.).

Consideramos esta segunda procesión del mes de octubre como rogativa porque la procesión en su día se realizó el 31 de agosto. Por regla general, cualquier procesión que se realizaba fuera de la fecha festiva debió ser considerada como un tipo de rogativa. De igual forma se presentó en la misma documentación de libramiento, la procesión a San Marcelo, el 17 y 25 de octubre de 1692. El 16 de setiembre de 1712, último día de los desagravios del Santo Cristo del Consuelo, se acordó hacer una procesión hacia la divina majestad por la epidemia y la falta de frutos que padeció la ciudad Lima (ACM, serie A, LAC, n. 10, 1712, fol. 155). El 16 de octubre de 1714 se acordó realizar una rogación pública por la dilatada esterilidad y aumento de frutos, desde la Catedral de Lima hasta la iglesia de Copacabana, a nombre de su divina majestad, en la cual participaron todas las comunidades y feligreses para bendición de los campos (ACM, serie A, LAC, n. 10, 1714, fol. 1v).

El 22 de febrero de 1719 se realizó una procesión en rogativa desde la catedral hasta la parroquia de San Sebastián contra la peste (AAL, sección papeles importantes, XXIII, 12, 1719, fol.3). El 9 de junio de 1720 se realizó una novena en la Catedral de Lima a la Señora del Rosario (ACM, serie G, Carpeta de cuentas n. 16, s. XVIII, s/f.), y en el mismo año, el 15 de julio, se realizó un octavario a la misma Santa (ACM, serie G, Carpeta de cuentas n. 16, s. XVIII, $\mathrm{s} / \mathrm{f}$.). Estos fueron libramientos distintos y no mencionan si en el último día de los novenarios u octavarios se realizaron procesiones, como la de 1710. El 18 de agosto de 1722 se dio licencia al convento de Santo Domingo para que realice una procesión en rogativa de las reliquias al final de su octavario, de tal forma que la divina majestad interceda contra la peste general. La procesión de ida a la catedral y vuelta al convento dominicano contó con la presencia de la feligresía y de la corte del Cabildo (ACM, serie A, LAC n. 10, 1722, fol. 77).

El cabildo civil no propuso esta rogativa, sino que fue aprobada por la mesa capitular. El 20 de julio de 1723 se propuso que se haga procesión general en rogativa a la virgen del Rosario y a Santa Rosa: "a la propia catedral Y que sea/ga este nobenario en orden a la sequedad y peste q se experimenta” (ACM, serie A, LAC, n. 10, 1723, fol. 94). El 24 de mayo de 1727 se realizó una procesión en rogativa a San Marcelo, abogado de los frutos, y de San isidro Labrador a la Catedral de Lima, donde fue colocado en el altar mayor, mientras que el 25 de mayo se hizo un misa al Santísimo Sacramento y se sacaron en procesión a los santos: "por tan dilatados años la esterilidad en la cosecha de trigos y por esta/ razón caresen delos estipendios que en los años pasados se persevian esperimentandose lo mismo en las demas rentas eclesiásticas [...] se dignase de faboresernos con la gral cosecha y abundancia de frutos" (ACM, serie A, LAC, n. 11, 1727, fol. 23). En 1729 se hizo una procesión en rogativa con un novenario dedicado a la Señora de las Mercedes, dirigida a la catedral y contra la esterilidad, fechada el 20 de febrero de 1730 (AHML, LCL, n. 34, 1730, fol. 216:).

Para finalizar, todas las rogativas que han sido encontradas tuvieron la predisposición de cambiar constantemente de santo mediador ante la divina majestad (Dios), quien intercedería ante los eventos extremos. Como menciona Lorenzo Huertas (2009), durante periodos críticos y de colapso se vislumbró la etnogénesis y la revitalización de paradigmas. Durante el periodo de cuarenta años se revitalizaron los cultos y la búsqueda de patrocinios divinos ante la esterilidad 
y las pestes. El 21 de octubre de 1715, se buscó la protección del Señor de los Milagros (AHML, LCL, n. 34, 1715, fol. 158v).

En 1730 la Virgen María Nuestra Señora de las Mercedes juró como patrona de los campos, y habiendo mejorado los buenos sucesos de los trigos, los:

...hacendados de los valles circumbesinos alegando que con la ocasión/ de la insolita y dilatada esterilidad de frutos experimentada en los campos se/ hallaran con los atrasos q eran notorios para cuio reparo y bersise mejoravan/ los tiempos habían echo repetidas de precauciones y de botas diligencias q no producían/ efecto alguno [a los otros santos y santas] (AHML, LCL, n. 34, 1730, fol. 216).

En total fueron encontradas 25 rogativas, incluidas las repeticiones por año en 1695 (5), 1705 (2), 1710 (2) y 1720 (2). Las rogativas de 1704, 1708, 1719 y 1722 fueron por epidemias, habiendo 13 rogativas por esterilidad, de las cuales las de 1712, 1723 y 1727 fueron por esterilidad y epidemias en la misma procesión. El novenario y octavario de 1720 no mencionan el motivo. Para los años 1695, 1705, 1710 y 1720, se escogieron las rogativas de mayor nivel de culto, con un total de 18 rogativas procesadas para cada año.

En la documentación del siglo XVIII sobre periodos preinstrumentales, según menciona Carcelén, hay datos directos: "cuando los testimonios [...] hacen referencia de manera puntual a inundaciones, aumentos no acostumbrados de la temperatura y de las lluvias, de la esterilidad de la tierra" (2009, p. 74). En las rogativas, el termino esterilidad caracteriza y es equivalente a todo evento extremo de indisponibilidad del agua, de origen climático, que desequilibra el funcionamiento ambiental de la estructura productiva; en este caso, el régimen agrícola, desde la siembra hasta la cosecha. De acuerdo a Hipólito Unanue, cuando variaban los estíos y el otoño a tendencias secas, "tanto mayor debe ser el temor de la falta de lluvia, la esterilidad, y los males que la acompañan" (Unanue, 1805, p. XLI).

No hay mención de rogativas por inundaciones o lluvias prolongadas. Su realización siempre fue después de haber experimentado el patrón ambiental que afectaba a la producción, cumpliendo al mismo tiempo un papel preventivo para que en la siguiente temporada agrícola no se repitiera el evento extremo o una epidemia. La misma existencia de rogativas propluvia y por epidemia en la misma procesión y de manera dilatada sugiere un patrón recurrente reconocible por los grupos sociales. En las rogativas, casi siempre, se mencionaron especificaciones adicionales relacionadas a la mayor solemnidad posible de la ceremonia, diferenciadas de las procesiones. También la amplitud geográfica como Reino, arzobispado, sierra y llano.

\section{Procesamiento de las rogativas}

Los criterios para establecer la intensidad de las rogativas consisten en cinco niveles de severidad climática. Para ello, hemos designado un valor de acuerdo a la información proporcionada por los documentos históricos. Previamente, hemos consultado los criterios de intensidad explicados por Barriendos (1995, 1999), para el caso de Catalunya, y por Garza (2014), para el caso de México central. Las dos propuestas coinciden en la relevancia del grado de solemnidad. De los cinco niveles de intensidad, solo difieren en el grado V. La diferencia radica en el espacio temporal trabajado por Barriendos del siglo XIV al XIX, teniendo mayor margen de tipificación y captación de eventos extremos del clima. El nivel I y II tienen el mismo acto litúrgico en ambos modelos. 
Para Barriendos (1995), el nivel III consiste en procesiones en rogativas a santuarios; el nivel IV, en la inmersión en el agua de reliquias o imágenes de advocaciones de especial veneración, y el nivel $\mathrm{V}$, en la peregrinación multitudinaria a un sitio sagrado, registrada solo cinco veces durante seis siglos. En el caso de México central, Garza (2014) tiene un espacio temporal que comprende del siglo XVI al XIX. El nivel III es un novenario sin procesión realizado en la catedral o santuario de la advocación elegida. El nivel IV son procesiones y novenarios en el santuario, o una procesión sin novenario en la catedral. El nivel V es la procesión de la advocación elegida, desde su santuario o altar especifico hasta el altar mayor de la catedral, pasando a través de las calles de la ciudad.

Las rogativas realizadas en el marco eclesiástico y civil, tanto en Europa como en América Latina, son fijadas en cinco grados de intensidad dependiendo de la circunstancia excepcional, permitiendo así una tipificación desde el grado máximo al mínimo: "su origen y características formales [de las rogativas] pueden ser muy dispares [...]. Su variedad hace difícil el establecimiento de una tipología cerrada" (Barriendos, 2005, p. 14). Según las rogativas expuestas en este trabajo y con información adicional de los mismos documentos, establecemos una tipología, primero identificando la de mayor grado de solemnidad y culto, para luego compararla con las tipologías de Barriendos y Garza.

Tabla 1. Rogativas propluvia y los niveles de crisis agraria por esterilidad de frutos

\begin{tabular}{|c|c|c|c|}
\hline Niveles y años & Tipo de rogativa propluvia & $\begin{array}{l}\text { Grado de } \\
\text { sequia }\end{array}$ & $\begin{array}{l}\text { Efectos en la } \\
\text { agricultura }\end{array}$ \\
\hline 1 & $\begin{array}{l}\text { Oraciones en silencia en una iglesia (Barriendos, 1995, p. } \\
\qquad 212 \text {, y Garza, 2014, p. 87) }\end{array}$ & Leve & Ninguna (preventivo) \\
\hline II & $\begin{array}{l}\text { Oraciones en voz alta en una o varias iglesias (Garza, } \\
\text { 2014, p. 212) y/o con reliquias en un altar durante meses } \\
\text { (Barriendos, 1995, p. 87) }\end{array}$ & Medio & $\begin{array}{l}\text { Daños poco } \\
\text { importantes }\end{array}$ \\
\hline $\begin{array}{l}\text { III } \\
1694,1703,1720 \text { (no } \\
\text { menciona motivo) }\end{array}$ & $\begin{array}{c}\text { Realización de novenarios, octavarios sin procesión en la } \\
\text { catedral (Garza, 2014), sermones panegíricos, novenarios, } \\
\text { octavarios y revelaciones en rogativa realizadas en la } \\
\text { catedral invocando al santo elegido }\end{array}$ & Grave & $\begin{array}{l}\text { Pérdida parcial de } \\
\text { cosechas }\end{array}$ \\
\hline $\begin{array}{c}\text { IV } \\
1693,1704 \text { (epidemia), } \\
1712,1719 \text { (epidemia) }\end{array}$ & Procesiones públicas a la parroquia del santo elegido & Muy grave & $\begin{array}{l}\text { Pérdida casi total de } \\
\text { cosechas }\end{array}$ \\
\hline $\begin{array}{c}\mathrm{V} \\
\text { 1692, 1695, 1705, } 1708 \\
\text { (epidemia), 1709,1710, } \\
\text { 1714, 1722 (epidemia), } \\
\text { 1723, 1727, 1729) }\end{array}$ & $\begin{array}{l}\text { Procesiones generales a la catedral con novenario y/o } \\
\text { octavario. Es el de mayor grado de culto de solemnidad } \\
\text { registrado en el documento }\end{array}$ & Critico & Crisis de subsistencias \\
\hline
\end{tabular}

Fuente: Criterios tomados de Garza (2014) y Barriendos (1995). Información extraída de la recopilación de rogativas halladas en los Libros del Cabildo de Lima (LCL), Libros de las actas capitulares, carpetas de cuentas (ACML) y cartas pastorales (BNP).

Para todas las rogativas del nivel V, se observa que: (1) Eran dos procesiones de ida y vuelta con las reliquias e imágenes. La ida consistía en llevar al mediador a la catedral para realizar un novenario y/o octavario; una vez finalizada se realizaba otra procesión por las calles hacia su resguardo en su parroquia o convento. (2) Participan todas las comunidades religiosas y funcionarios. (3) Las calles y plazas se adornan. (4) Se recorre el cementerio, valles y se conjura o bendicen los campos. Todas estas especificaciones eran de grado explícito en los documentos. En el nivel IV se mencionan solamente procesiones realizadas en la parroquia del santo, y en el nivel III solo se realizan novenarios u octavarios en la catedral. En el nivel III se incluyen los sermones panegíricos o revelaciones porque formaban parte de una festividad en rogación a la catedral pidiendo el patrocinio divino ante los eventos extremos; el nivel mediador es alto y su culto es equivalente a los novenarios y/o octavarios que están en el nivel III. Al tener este grado 
de solemnidad y apreciando que tanto Garza (2014, p. 87) como Barriendos (1995) proponen que el nivel I comprende oraciones simples, y el II oraciones en voz alta o con reliquias en el altar, se puede considerar que son equivalentes al nivel III. La tipología de intensidad de nivel III, IV y V presentado en este trabajo concuerda con la propuesta de Garza (2014, p. 87).

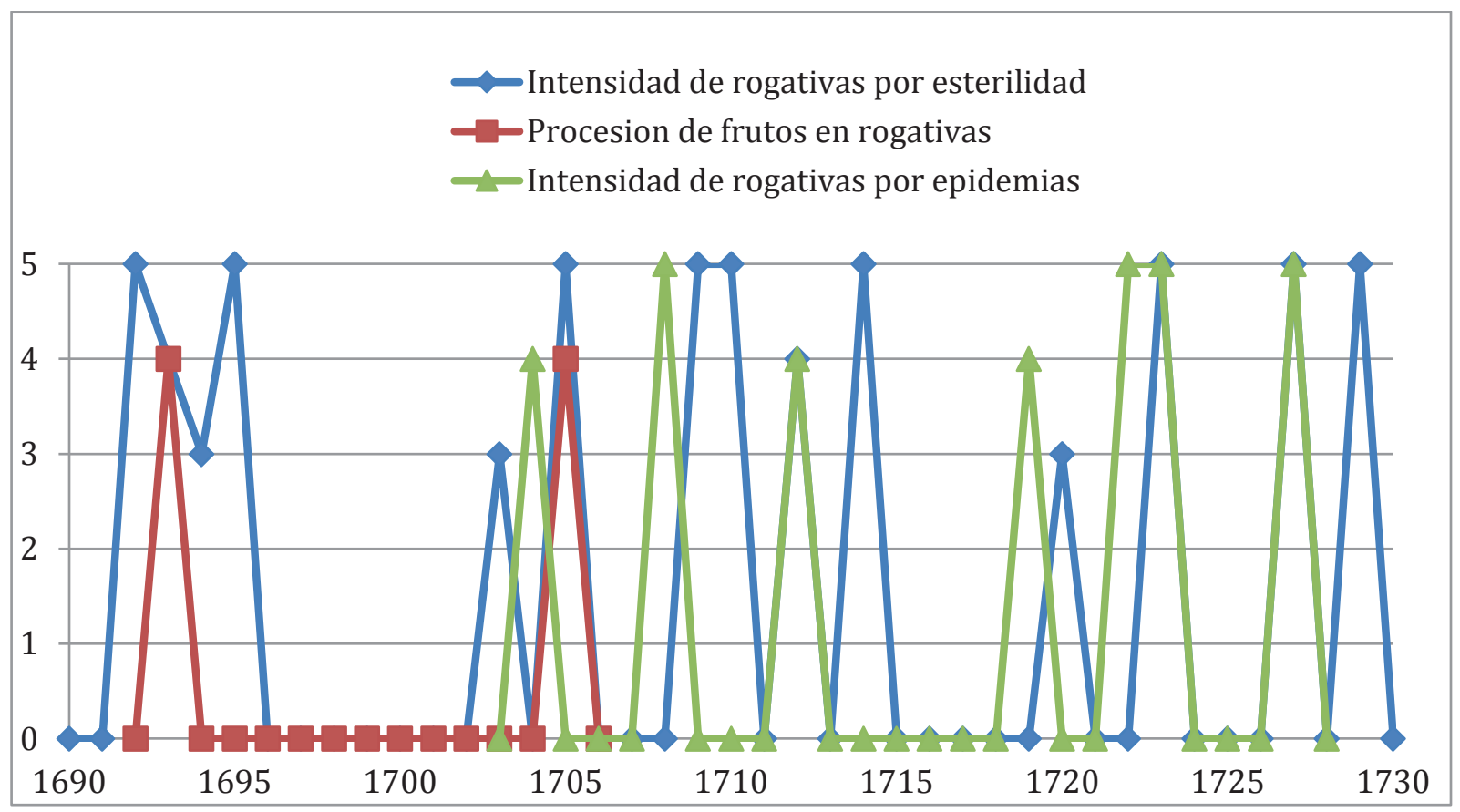

Figura 1. La variabilidad climática en Lima: las coyunturas climáticas en las procesiones en rogativas (1690-1730)

Fuente: Información recopilada de las rogativas halladas en los Libros de Cabildo de Lima (LCL), los Libros de actas capitulares y carpetas de cuentas (ACML) y cartas pastorales (BNP).

La variabilidad climática de 1690 a 1730 es representada por cuatro crisis climáticas agrupadas por coyunturas. Las rogativas propluvia por esterilidad son un indicador de variación hidrológica, y las rogativas por epidemias, un indicador biológico del clima. La primera coyuntura es de 1692 a 1695: 1692, 1693, 1694 y 1695, la segunda de 1703 a 1705: 1703, 1704 y 1705, la tercera de 1708 a 1714: 1708, 1709, 1710, 1712 y 1714, y la cuarta de 1719 a 1729: 1719, 1720, 1722, 1723,1727 y 1729.

De los niveles de crisis agrarias registrados en la tabla 1, solo usaremos las rogativas propluvia (por esterilidad), las cuales son directamente proporcionales a la situación deficitaria de las temporadas agrícolas y, teniendo en cuenta que los grupos sociales de hacendados, religiosos y funcionarios estuvieron interesados en la realización de la rogativa propluvia y de la intensidad del culto, consideramos que estas fueron un intento de mitigación de las sequías, entendidas por cierto como producto de la ira de Dios durante esos años.

El cultivo principal aludido en las rogativas fue el trigo, sustento de ingreso fiscal y de abasto en la ciudad de Lima, en donde se pueden identificar las siguientes intensidades de rogativas por esterilidad: nivel III $(1694,1703)$, con dos años de pérdida parcial de cosechas, nivel IV (1693, 1712), con dos años de perdida casi total de cosechas, y nivel V $(1692,1695,1705,1709,1710$, 1714, 1723, 1727, 1729), con 9 años de crisis de subsistencias. En total, 13 años de rogativas por esterilidad de las 18 procesadas en las coyunturas agrarias de 1690 a 1730. 
La crisis agrícola a fines del siglo XVII e inicios del XVIII en Lima y el centro del Perú: Método historiográfico para el conocimiento...

Tabla 2. Relación de las rogativas por esterilidad y epidemias como marcadores climáticos del ENSO en el período colonial

\begin{tabular}{|c|c|c|c|c|}
\hline \multicolumn{5}{|c|}{ Las rogativas por esterilidad y epidemias como señal de ocurrencia del ENSO (1690-1730) } \\
\hline Niño & Niña & Rogativas & Esterilidad y epidemias & Lluvias \\
\hline \multirow[t]{2}{*}{ 1692: W } & & 1692: V & EST & \\
\hline & & 1693: IV & EST & \\
\hline 1694: $S$ & & 1694: III & EST & \\
\hline \multirow[t]{2}{*}{ 1695: W } & & 1695: V & EST & \\
\hline & 1696: VS & & & $x$ \\
\hline & & & & \\
\hline & & & & \\
\hline \multicolumn{5}{|l|}{ 1700: W } \\
\hline & 1701: M & & & 4 \\
\hline & 1702: M & & & \\
\hline & & 1703: III & EST & \\
\hline & & 1704: III & EST - EPI & \\
\hline & & 1705: V & EST & \\
\hline \multicolumn{5}{|l|}{ 1707: W } \\
\hline & 1708: S & 1708: V & EPI & \\
\hline 1709: W & 1709: M & 1709: V & EST & \\
\hline 1710: W & & 1710: V & EST & \\
\hline 1712: W & & 1712: IV & EST -EPI & \\
\hline \multicolumn{5}{|l|}{ 1713: M } \\
\hline \multirow[t]{3}{*}{ 1714: W } & & 1714: V & EST & \\
\hline & 1715: S & & & $x$ \\
\hline & 1716: $S$ & & & \\
\hline \multicolumn{5}{|l|}{ 1718: $E$} \\
\hline 1719: $S$ & & 1719: V & EPI & \\
\hline 1720: W & & 1720: III & ----- & \\
\hline \multicolumn{5}{|l|}{ 1721: W } \\
\hline 1722: M & & 1722: V & EPI & \\
\hline 1723: E & & 1723: V & EST -EPI & \\
\hline \multirow[t]{2}{*}{ 1724: W } & 1724: M & & & \\
\hline & 1724: M & & & \\
\hline \multicolumn{5}{|l|}{ 1726: $S$} \\
\hline & & 1727: V & EST -EPI & \\
\hline 1728: $E$ & & & & 5 \\
\hline \multirow[t]{2}{*}{ 1729: W } & & 1729: V & EST & \\
\hline & 1730: W & & & \\
\hline
\end{tabular}

Fuente: Información de las rogativas extraída de los Libros de Cabildo de Lima (LCL), Libros de las actas capitulares, carpetas de cuentas (ACML) y cartas pastorales (BNP). La propuesta de la intensidad de El Niño ha sido tomada de Gergis y Fowler (2008). 
Al comparar las series ENSO del cuadrante 3.4 elaborado por Gergis y Fowler $(2008$, p. 28) en sus etapas de El Niño y La Niña (débil, moderado, fuerte, muy fuerte y extremo), se tiene que estos cuadrantes son importantes porque influyen en las sequías y tienen conexiones globales. También influyen en las lluvias producidas por el Niño en la costa norte y centro del Perú, en especial en Lima, (en la tabla 2, "X" representa anomalías en la costa). Los niveles 4 y 5 son de intensidad de lluvias extraordinarias y torrenciales (Hocquenghem y Ortlieb, 1992, pp. $205-$ 206), los cuales, al ser complementados con los indicadores de rogativas (propluvia/epidemias), da como resultado que las cuatro crisis climáticas tuvieron una relación con los períodos de actividad ENSO y de desglaciación en las regiones de los trópicos de la cordillera de Bolivia a fines del siglo XVII (1648-1700). Dentro de ese rango se da inicio a un retroceso que ningún avance durante los siglos XVIII (1722-752) y XIX (1781-1818) ha podido superar en el cerro glaciar Charquini $16^{\circ} \mathrm{S}$ (Rabatel et al, 2005).

En el estudio de Villalba, las desglaciaciones y avances estuvieron en relación con los períodos ENSO, en la región central de Chile y norte de Patagonia: "la culminación de estos avances neoglaciares ha sido estimada entre el fin del siglo XVII y comienzos del siglo XVIII" (1994, p. 456). Según Luterbacher et al (2001), la reconstrucción de los períodos fríos de la Pequeña Edad de Hielo ocurrida en Europa central, occidental y norte, indica que la NOA (índice de la oscilación del Atlántico norte) estuvo en su etapa negativa de 1655 a 1710. Los inviernos más severos en 1684-1695 y 1709 fueron fríos y secos. En Italia, en la zona de Venecia, un fuerte invierno ocurrió en 1684 y un gran invierno en 1709, y entre 1725 y 1730, el clima fue cálido (Camuffo, 2014). Mientras que Grove y Adamson (2018) mencionan que las sequías de 1600 a 1679 en los trópicos del sur de Asia y norte de África, están relacionadas con los períodos fríos de la Pequeña Edad de Hielo.

Para entender las teleconexiones e interconexiones entre una célula de presión del Atlántico norte y América del sur, es necesario el enfoque ambiental de la circulación océano-atmosférica: "si una región experimenta un excesivo aporte de calor y humedad, en otras partes del mundo responde con el aire más fresco y seco a través de esta 'auto-compensación" (Caviedes, 2001, p. 38). Comparando algunos años de rogativas con las referencias de años de inviernos fuertes en Europa (1690, 1692, 1693, 1694, 1695, 1696 y 1709), se tiene que con el ingreso de vientos del oeste en 1693, el NAO estuvo en fase negativa, influyendo en las zonas de Europa. Mientras que en el océano Pacifico central y oriental se presenta un Niño débil en 1692 (en Lima una rogativa nivel V), un Niño fuerte en 1694 (en Lima una rogativa de nivel III), una Niña muy fuerte en 1696 (en Lima 5 rogativas durante los meses de julio, agosto y octubre de 1695). En 1708, una Niña fuerte (en Lima una rogativa por epidemia nivel IV) y en 1709 un Niño leve y una Niña moderada (en Lima una rogativa de grado V). A partir de la influencia de la variabilidad climática global y regional con las interconexiones hemisféricas en Europa y Sudamérica entre la NAO y el ENSO, se puede relacionar las referencias de grandes inviernos en Europa en 1690, 1693, 1695, 1696 y 1709 con una NAO en fase negativa. Esta serie de rogativas presentadas funciona como señales de su ocurrencia en los períodos preinstrumentales, en especial los fuertes años secos, denominados como años de esterilidad, de gran alteración en las estaciones agroclimáticas del período colonial.

\section{La crisis demográfica y agrícola entre los siglos XVII y XVIII}

Durante el siglo XVIII, en el área central del Perú se presentaron innumerables evidencias de la variabilidad climática. En el caso de las zonas aledañas a Lima, las diversas solicitudes de visitas que pudimos encontrar sirvieron para establecer nuevas tasas del tributo indígena pagado en cada comunidad y como indicadores más cercanos a la realidad. 
Para la provincia de Huarochirí, tenemos las solicitudes de los caciques del repartimiento de Chaclla, quienes lograron que se hicieran cinco procesos de visitas a lo largo del siglo XVIII: 1703, 1724, 1725-26, 1729 y 1751 (Gentile, 1976). A través de cada una de ellas, podemos ver que las autoridades españolas confirmaron la caída demográfica de esta zona, al extremo de que todo el aparato burocrático colonial se alarmó.

En 1703, una de las causas específicas de la caída demográfica, según el cacique de Chaclla, fue que "se mantiene con bastante rigor y armonía la epidemia general" (Archivo General de la Nación, Derecho Indígena, c. 307, 1703, f. 2v). Esta epidemia se puede identificar como resultado de las copiosas lluvias producidas durante algunos años y sus respectivos extremos secos iniciados en 1694 (Archivo General de la Nación, Derecho Indígena, c 189, 1706), ya que desde este tiempo se desarrollaron visitas para comprobar la caída demográfica y de la producción, especialmente de uno de los productos de primera necesidad como el trigo, así como también el déficit de abastecimiento de agua para riego y consumo humano.

Los detalles de la caída de la productividad agrícola en el Perú, sobre todo en las últimas décadas del siglo XVII, son aplicados por Oscar Febres (1964). En la provincia de Yauyos se puede encontrar la siguiente situación sobre la escasez de agua:

Sin otra cossa alguna para sus sustento y no es de menos consecuencia que el dicho corregidor paga a diez pesos por vasija por ser sacada de agua pie requemada que las mas en [...] dalos en lugar de agua ardiente parece tinta de calidad que no [se] puede beber y aun siendo assi nos obliga a que le paguemos quarenta pesos por cada vasija (Archivo General de la Nación, Derecho Indígena, c. $187,1703 f .1 v)$.

En el caso de la hacienda de Carabayllo, se señala que:

La esterilidad y ruina de estos años... Asido tal la injuria de los tiempos y tan intolerable la esterilidad que sea continuado en todos ellos principalmente en la semilla de trigo que es el único fruto que se coxe en dicha hacienda por distar de esta ciudad dos leguas (Archivo Arzobispal de Lima, Capítulos, Leg. 26, Exp. XIII, 1701, fol. 16).

Esta situación se hizo extensiva a toda la costa y los valles interandinos debido a los efectos de El Niño de 1701.

Unido a todo esto, desde 1714 hasta 1720 se presentó una gran epidemia que asoló un gran radio desde Huamanga hasta el Río de la Plata, manifestando su peor violencia en la zona del Cusco, en 1730, en donde cobró el mayor número de víctimas, en un promedio de 100 al día entre los meses de agosto y setiembre. Testigos cusqueños compararon esta epidemia con la peste de 1589. El número final de víctimas fue calculado en unos 20 mil muertos en la ciudad del Cusco y otros 40 mil en las poblaciones aledañas. Por ello, esta epidemia fue denominada en la historiografía cusqueña como "la gran peste" (Vargas Ugarte, 1956, pp. 92-93). Esta coyuntura de epidemias se relaciona directamente con los Niños muy fuertes de 1687, 1688, 1701,1720 y 1728.

\section{Lima sin abasto. Los arrendatarios a inicios del siglo XVIII}

La variabilidad climática que afectó a la zona central del Perú hizo que, durante las primeras décadas del siglo XVIII, Lima atraviese por una escasez de abastecedores y arrendatarios en productos importantes. Un breve estudio sobre la situación de estos personajes ayuda a ilustrar la 
situación crítica que vivió la ciudad. El abastecimiento de carne de carnero y el arrendamiento del mojonazgo (impuesto a la venta de vino y aguardiente) fueron motivo de creciente preocupación por los miembros del cabildo de la ciudad.

\section{Lima sin carne: el problema del abasto de carne de carnero de Castilla}

Empecemos por analizar la situación del abasto de carne de carnero de Castilla en la ciudad de Lima. En 1701, se sacaron a postura el arrendamiento de la carne de Castilla. Al no haber un postor que llenase las expectativas del cabildo, se tomaron las medidas necesarias para suplir esta falta. El 21 de mayo de 1701 se dispuso que se retiraran todos los pregones debido a que no se encontró un postor ideal para tal efecto, resolviéndose por ello que cualquiera que tuviera dos mil cabezas de ganado las pudiera vender en el rastro (lugar en donde se comercializaba la carne), hasta cumplir las 25 mil cabezas que necesitaba la ciudad. Del mismo modo, se indicó que cualquier criador podía traer su ganado para ser vendido en la ciudad de Lima (AHML, LCL, n. 33, Cabildo del 21 de mayo de 1701), como medida provisional para suplir la escasez de este recurso.

Recién a fines de ese año se logró encontrar abastecedores ideales para tal efecto. La responsablidad recayó en Juan Díaz de Arcaya y en Sebastián de Torres, aunque ambos señalaron la necesidad de reparos en los rastros de la ciudad a través de dos informes que presentaron al cabildo el 14 de setiembre de 1701 y el 21 de octubre del mismo año (AHML, LCL, n. 33). La situación de los abastecedores mejoró al siguiente año, pues notificaron a la ciudad que poseían 60,500 cabezas de ganado distribuidas en chacras alrededor de la ciudad, como las de Trapiche, Casa Blanca, Guarangal, Punchauca, entre otras (AHML, LCL, n. 33, cabildo del 11 de agosto de 1702).

Sin embargo, esta situación de bonanza entre los criadores de carne de Castilla finalizó en el segundo lustro de la década. En las sesiones del cabildo de la ciudad hay información sobre la mala calidad de la carne que se encontró en los rastros. En 1707 se trató en el cabildo de la mala situación de abasto de la carne de Castilla:

Se confirió mediante la proposición del alcalde Gerónimo de Agüero sobre la mala calidad de la carne de carnero y la falta de la que ay en los rastros y la buena se saca para regatonear y se mando que los señores alcaldes y fieles ejecutores lo hagan con el celo que acostumbran y visiten los rastros y den providencia para que aya buena carne en ella y eviten los desordenes que ay de pasar por junto a la carne y regatonearla castigando a los regatones y se le notifique al obligado de ellas cumpla con la obligación de su cargo según el remate teniendo buena carne y abastecido los rastros y no tenida por puntual i en pie carnero alguno se les debía penar otros demás que parecieres conveniente de los ganados y chacras que tiene conforme a lo acostumbrado para que se pase hacer vista de ojos con apersevimiento (AHML, LCL, n. 34, cabildo del 16 de marzo de 1707).

La escasez del producto, como se observa en las quejas de los alcaldes ordinarios, trajo consigo la aprisión de los regatones, práctica condenada en todos los dominios españoles. Esta consistía en la aparición de una suerte de mercado negro al margen de las formas oficiales de venta. Los regatones compraban la mejor carne fuera del rastro y la vendían a mayores precios, ocasionando quejas entre los habitantes de Lima. Ante la falta de carne de buena calidad, esta práctica se mantuvo durante los años de escasez. 
La situación de falta de carne hizo que los arrieros de las chacras de las cinco leguas solicitaran al cabildo de la ciudad un permiso para aumentar la cantidad de cabezas de ganado que podían criar. Se solicitó que se aumenten de 50 a 200 cabezas de ganado, debido a que los arrendatarios no podían cumplir con su función. (AHML, LCL, n. 34, cabildo del 7 de octubre de 1707). Años más tarde, esta medida ocasionó fuertes reclamos de los abastecedores oficiales, pues afectaba directamente en las ganancias de este arrendamiento.

Los problemas fueron tan graves que para 1709 el cabildo informó que el arrendatario del ganado de Castilla no tenía más de 31 mil cabezas de ganado desnutridas y en mal estado (AHML, LCL, n 34, cabildo del 10 de julio de 1709). Se hace referencia a la falta de alfalfares, por lo cual el cabildo ordena la compra de los que sean necesarios y la plantación de alfalfa en cuatro chacras grandes. La ciudad de Lima buscó adaptarse desesperadamente. A lo largo de 1709 se ordenó la compra y arrendamiento de alfalfares para la cría de ganado de Castilla: "Se dijo que encuentren para el tiempo de agosto alfalfares maduros y que metan ahí todos los ganados que pudiesen. Y que para el tiempo de las esterilidades del año que viene separen algunas chacras con alfalfares" (AHML, LCL, n. 34, cabildo del 18 de julio de 1709).

Durante esos años, los arrendatarios de la carne de Castilla no pudieron mantener a la ciudad abastecida, por lo que el cabildo se vio en la necesidad de traer ganado desde otras provincias del virreinato. Desde Guaylas (actual Ancash) entraron a Lima, en varios envíos entre 1708 y 1710 , ganado de Castilla para suplir la falta de este producto y por la imposibilidad de los arrendatarios para cumplir con su abastecimiento (AHML, LCL, n. 34).

\section{Los arrendatarios del mojonazgo de vino y aguardiente en problemas}

En el mismo año en que se realizaron los remates del abasto de carne, se vio también el abasto del mojanazgo de vino y aguardiente, entregándoselo a Joseph Gindon. En 1701, el arrendatario de este impuesto se quejó ante el cabildo de los problemas por los que atravesó al momento de cobrar este derecho. Señaló como la razón principal de su deterioro que los productores ponían de pretexto que el vino que transportaban era en calidad de encomienda y no de venta. Esto, sin duda, fue una estrategia usada por los productores para evitar el pago de los impuestos al arrendatario (AHML, LCL, n. 33, cabildo del 2 de setiembre de 1701). Se puede advertir que junto con las inclemencias de la variabilidad climática, estas prácticas evasoras favorecían al contrabando registrado para inicios del siglo XVIII (Vargas Ugarte, 1966) Este arrendatario no pudo cubrir el monto pactado, por lo que con el correr de los años no pudo obtener ninguna ganancia de la administración de este impuesto. Es muy probable que los productores decidieran vender el vino y aguardiente a través del contrabando para obtener mayores beneficios económicos.

Para enero del próximo año, la situación del arrendatario del mojonazgo era muy mala, ya que pidió una rebaja de los 800 pesos anuales que estaba obligado a pagar, puesto que se siguieron cometiendo fraudes al momento de la recolección de este impuesto, pero también por la baja producción de vino y aguardiente, consecuencia directa de la variabilidad climática (AHML, LCL, n. 33, cabildo del 10 de enero de 1702). La producción de vino fue tan mala entre 1701 y 1702 que el recaudador de este impuesto no encontró otra solución que huir de la ciudad dejando a su fiador con muchos problemas para cumplir con esta obligación. Dicho evento quedó registrado en la súplica que este hizo al cabildo para que se le libere de esta responsabilidad o que se le otorguen facilidades de pago:

Se vieron los autos de Sebastián de la Portilla en que pretende se de por libre de la fianza que yso a Joseph Gindon del arrendamiento del mojonazgo del vino de 
esta ciudad y puerto del callao y en atención que estaba este derecho rematado en menor cantidad de los ochocientos pesos por que se remata al susodicho y que el ultimo remate fue en quatro cientos y diez pesos en que hay tanta diferencia ya que al presente no se vende vino y esta tan atrasada esta cobranza que el dicho Joseph Gindon se ausento huyendo de esta obligación y dejando con la carga de ella al fiador vinieron todos los señores en que el tiempo de año y medio que le falta por cumplir dicho arrendamiento se le revajen a razón de doscientos pesos cada año y provea a razón de seiscientos pesos a esta ciudad (AHML, LCL, n. 33, cabildo del 16 de octubre de 1703).

El cabildo no tuvo otra alternativa que acceder a las rebajas que pidió el fiador en los cobros de este impuesto, ya que no se encontraron mejores postores para el cobro del mismo. Y por varios años no se logró encontrar algún arrendatario para que administre el mojonazgo.

Recién para el año de 1705 se encontró a un arrendatario que presentó una postura que el cabildo juzgó por conveniente. En los libros de cabildo se informa:

Melchor de Soria hace postura al mojonazgo de vino por 6500 pesos a razón de 500 pesos en cada un año por 8 años y se reconoce seguir de utilidad a los propios por lo decaído que se halla dicha postura y aver quebrado el principal fiador y juzgar que no habrá persona que haga postura a él. Con la condición de no sacarlo a pregón (AHML, LCL, n.34, cabildo del 5 de febrero de 1705).

Una semana después, el cabildo resolvió otorgarle a Melchor de Soria el derecho al mojonazgo, reconociendo que la baja producción del vino provocó que no hubiera más interesados en dicha postura.

No solo el cabildo civil tuvo problemas para recaudar sus derechos e impuestos. Durante los mismos años, llegaron al cabildo eclesiástico los pedidos de rebaja de diezmos de los partidos de Ica, Pisco y Nazca, aduciendo que el precio del aguardiente se había rebajado considerablemente, problema que se reconoció con la concesión de la rebaja (LAC, serie A, n. 8,1705 , fol. 184).

Para esta primera década del siglo XVIII, la producción del vino y el aguardiente decayó. Los obligados a este arrendamiento tuvieron constantes problemas para cubrir los pagos establecidos. En la siguiente tabla se muestran a las personas que se hicieron cargo del arrendamiento del mojonazgo entre 1700 y 1720 . Según se puede apreciar en las primeras dos décadas, ninguno de los arrendatarios pudo mantener sus obligaciones con la ciudad.

Tabla 3. Arrendatarios del mojonazgo de vino y aguardiente entre 1701 y 1723

\begin{tabular}{|l|l|l|}
\hline \multicolumn{1}{|c|}{ Arrendatarios } & \multicolumn{1}{|c|}{ Años } & \multicolumn{1}{c|}{ Condición } \\
\hline Joseph Gindon & $1701-1703$ & 800 pesos anuales, huyó de la ciudad dejando el arrendamiento \\
\hline Sebastián de la Portilla & $1703-1705$ & 600 pesos anuales, fiador de Joseph Gindon, tomó el cargo cuando este huyó \\
\hline Melchor de Soria & $1705-1713$ & 500 pesos anuales por ocho años (como no puede pagar, se le hace rebaja de 2000 pesos) \\
\hline Nicolás Alburria & $1713-1716$ & $\begin{array}{l}6500 \text { pesos en enero de } 1715, \text { pide se le rebajen } 600 \text { pesos, en julio de } 1715 \text { hace suelta del } \\
\text { derecho }\end{array}$ \\
\hline Gregorio de Losa & $1716-1723$ & 6500 pesos (pago total del arrendamiento) \\
\hline Gregorio de Losa & $1723-?$ & 6500 pesos (pago total del arrendamiento) por no haber mejor postura \\
\hline
\end{tabular}

Fuente: Registros de las sesiones del cabildo civil de la ciudad de Lima. 


\section{La variabilidad climática y los arrendamientos}

Como es evidente, la fuerte variabilidad climática por la que atravesó la ciudad de Lima en la primera década del siglo XVIII, produjo una caída en la producción económica de la ciudad. La caída de la producción de carne de carnero, vino y aguardiente es un indicativo del efecto de la variabilidad climática y, sobre todo, consecuencia de los fenómenos naturales recurrentes como el ENSO. En una época en donde aún no se tenía métodos eficaces para mediciones climáticas exactas, el fracaso de los arrendatarios, al intentar cubrir sus obligaciones, es un valioso indicador de las consecuencias del paso de fenómenos naturales de significativa importancia.

Por ejemplo, es común entre las quejas de los abastecedores de carne de Castilla la falta de pastos para criar su ganado. Por esto es que en la mayoría de los casos las cantidades que tenían en sus corrales no satisfacían a los consumidores de la ciudad, que día a día acudían a los rastros. Del mismo modo, los productores de vino evadían el pago de sus impuestos al arrendatario del mojonazgo, tanto por el creciente contrabando como por las inclemencias de la variabilidad climática existente. Es evidente que Lima atravesó por ciclos de lluvias y sequías importantes que hicieron que la producción de estos productos se tornara incierta, a lo que el cabildo buscó desesperadamente darle soluciones rápidas. El estudio del manejo de estos arrendamientos por parte del cabildo civil de Lima ayuda a ver cómo Lima respondió a los momentos de crisis que produjo la variabilidad climática. Esto lo convierte en una fuente de considerable valor para reconstruir el pasado climático de la ciudad.

\section{La destrucción de la infraestructura agrícola a mediados del siglo XVIII}

Una nueva coyuntura de crisis se comenzó a gestar desde 1743, año en que se aprecian las consecuencias de la variabilidad climática. A estas se unieron las primeras medidas políticas de reforma fiscal del Estado español. A la población indígena se le impuso el pago de la alcabala y una serie de tributos a todos los productos de Castilla - de origen hispano- a los denominados productos de la tierra, es decir, los de origen andino (Archivo General de la Nación, Superior Gobierno, leg. 9, c. 175, 1743, f. 12). Todos ellos producidos en las comunidades indígenas ubicadas en los contornos de la ciudad de Lima.

Los testimonios de importantes científicos como Pedro Peralta, Antonio Ulloa y Jorge Juan pusieron de manifiesto los problemas que se suscitaron desde 1743. Para Peralta el inicio del invierno de ese año fue bastante frío, perjudicando la producción de trigo (Peralta, 1721-1747), mientras que para Ulloa y Juan ese invierno en el área costera del Pacífico sudamericano fue uno de los más fríos, ocasionando en Lima: "constipaciones y fluxiones, de que murió mucha gente de modo que parecía contagio; y aunque son estas muy comunes en semejante tiempo, no tan peligrosas como en aquel año" (Ulloa y Juan, 1748).

El terremoto del 28 de octubre de 1746, que produjo la destrucción de la infraestructura hidráulica de la ciudad y de la zona agrícola aledaña, produjo una mayor escasez de agua, lo que unido al incremento de la temperatura, posibilitó el desarrollo de una serie de epidemias que terminaron por matar a unos 2000 habitantes desde noviembre de 1746 hasta febrero de 1747 (Vargas Ugarte, 1956).

En particular, esta escasez se presentó en varias zonas de Huarochirí, lo que a su vez generó una serie de conflictos, como el de los indios de los pueblos de Chauca y Otao en el repartimiento de Chaclla, quienes reclamaron el acceso a más tierras para su ganado y 
los cultivos destinados al abastecimiento de Lima (Archivo General de la Nación, Derecho Indígena, c. 825, 1749).

A los efectos moderados del Niño producido en 1750 se unió el problema constante de la escasez de agua, a tal extremo que en varias zonas de Lima se tuvo que realizar nuevos repartimientos de riego, superando lo establecido por las autoridades coloniales en el siglo XVII (Archivo General de la Nación, Juzgado de Aguas, c. 3.3.3.7, 1672, f. 6).

\section{La necesidad de medición sistemática durante la segunda mitad del siglo XVIII}

Después de las coyunturas críticas de 1700 a 1715 y de 1743 a 1752, se suscitaron más años con manifestaciones irregulares del clima, las que podemos explicar mediante el análisis de las gráficas basadas en la elaboración de la Serie de la temperatura de Lima durante el siglo XVIII y así establecer algunas pautas de interpretación del desenvolvimiento del clima en esta zona del Perú.

Lo primero que podemos establecer es la existencia de un cambio climático real, que se acrecentó con la participación de los habitantes de la zona en procesos como la modificación de la vegetación, del suelo y de los sistemas de riego y drenaje, así como por la deforestación, creación de cuencas artificiales, edificaciones, urbanizaciones e industrias. Esta variabilidad se reflejó también en un incremento de la temperatura promedio entre 1754 y 1800 en unos 0.20 grados centígrados, mientras que las máximas en el mismo lapso se incrementaron en 0.70 grados y las mínimas en unos 0.25 grados.

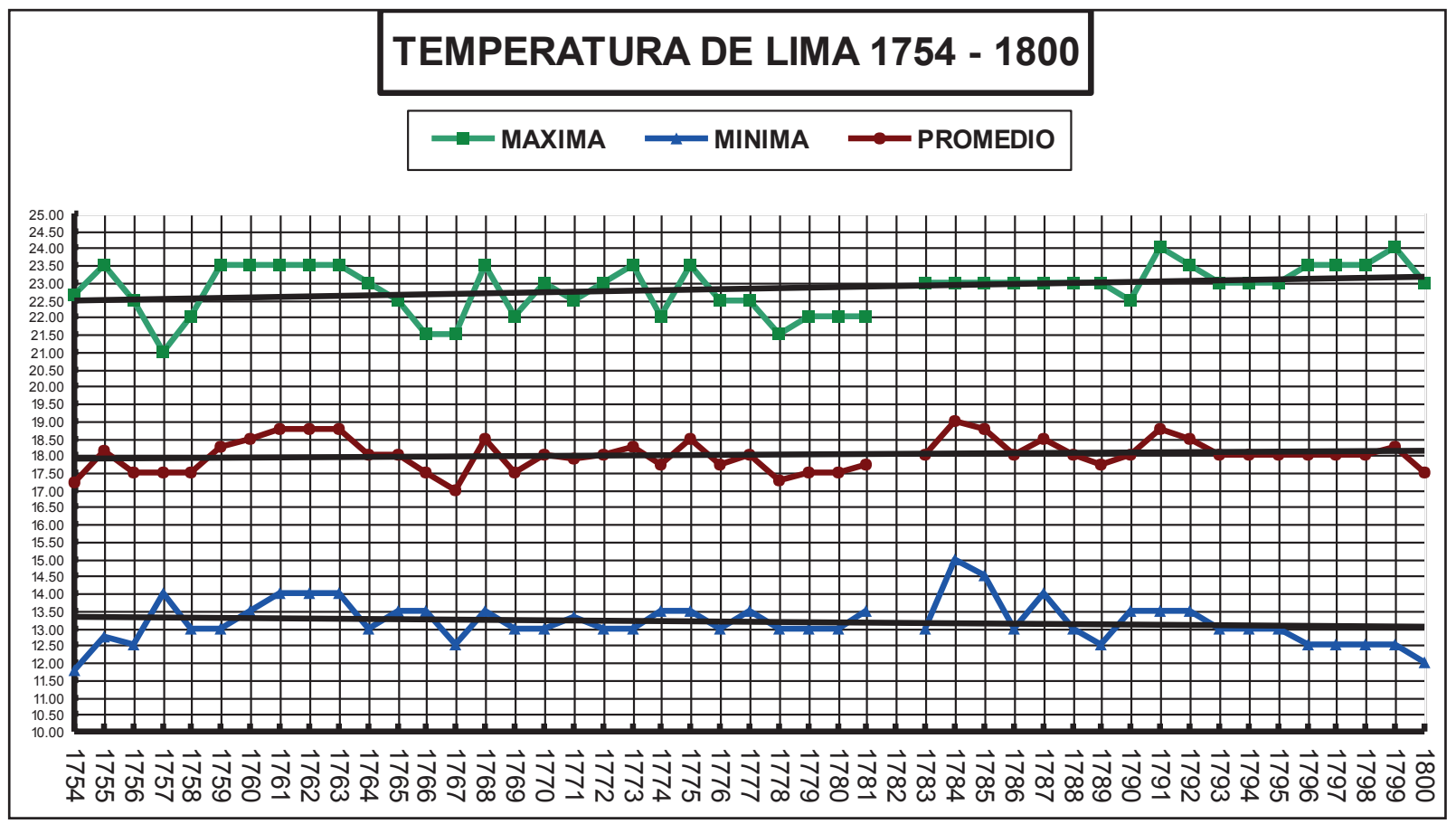

Figura 2. Tempertaura de Lima 1754-1800

Fuente: Serie de la temperatura de Lima durante el siglo XVIII

\section{La crisis climática a fines del siglo XVIII}

Durante la última década del siglo XVIII, la prensa otorgó a los escritores la posibilidad de "contar con un colectivo de testigos y jueces y de convertir sus puntos de vista sobre la 
naturaleza y la sociedad en un asunto público, es decir, en conocimiento" (Nieto, Castaño y Ojeda, 2005, p. 96). La publicación del Mercurio Peruano fue una clara muestra de esta tendencia ilustrada. En 1791, fueron publicados una serie de números que discutieron temas referentes a los entierros eclesiásticos y lo perjudicial que resultaron para la salud, sobretodo en el verano: "el ambiente de estas Iglesias en tiempo de verano tiene un mal olor, que se percibe sensiblemente aun en medio del incienso que en ellas se quema" (Rosi y Rubí, 17 de febrero de 1791, fol. 125).

En este periódico también se publicaron mediciones de temperatura entre 1791 y 1794 , elaboradas por Fray Francisco Romero, período en el que se manifestó uno de los Niños de mayores consecuencias y daños registrados, sobretodo en la costa norte del Perú. En el caso de Lima se pudo observar que la temperatura promedio se incrementó en $1.25^{\circ} \mathrm{C}$, con respecto a las medias promedio de los años anteriores. (Romero, 1791, 1994).

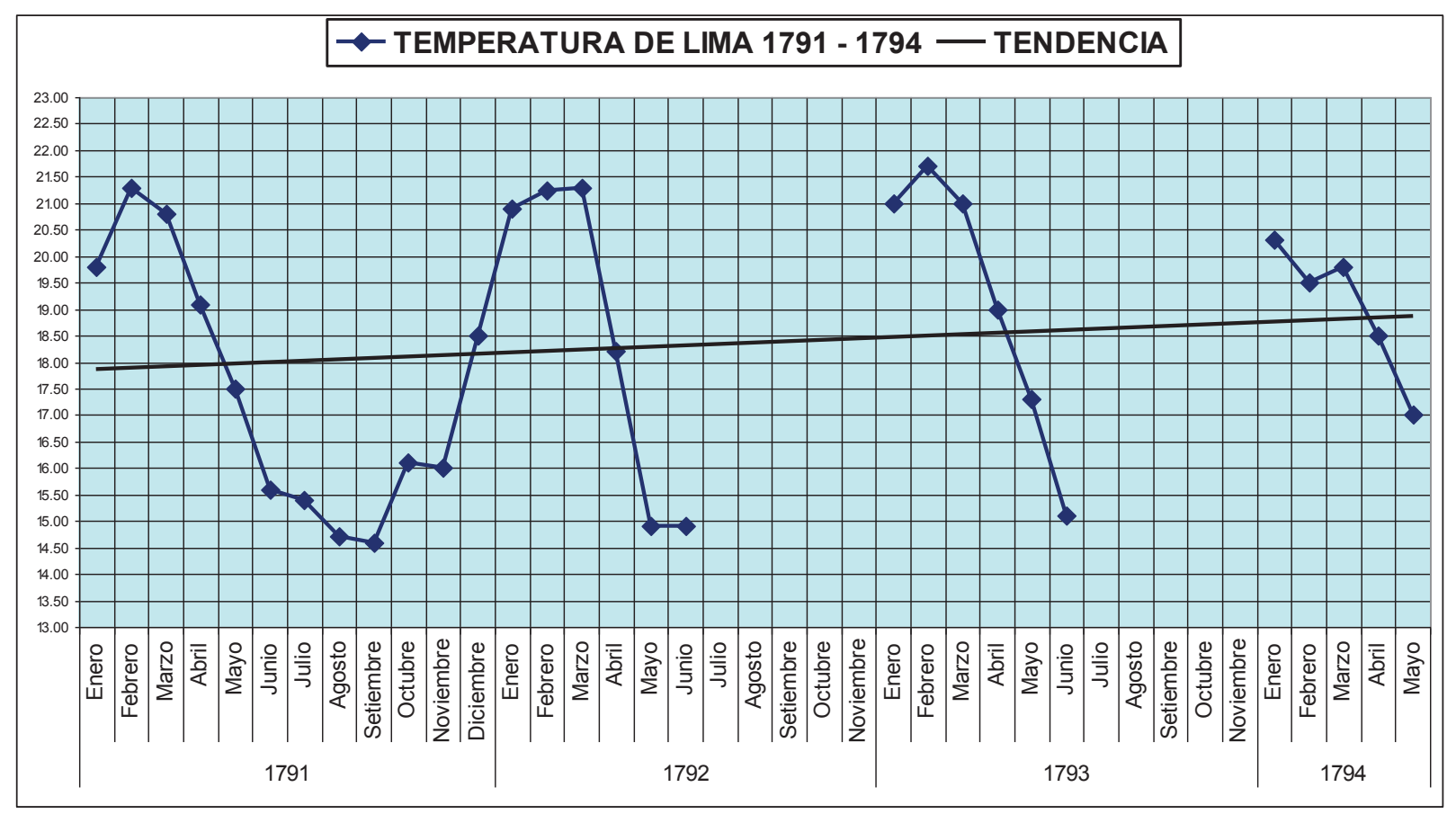

Figura 3. Temperatura de Lima 1791-1794

Fuente: Temperatura de Lima entre 1791-1794, Francisco Romero 1791-1994.

\section{Conclusiones}

Desde fines del siglo XVII hasta fines del XVIII, el centro del Perú fue azotado por catástrofes naturales, especialmente de tipo climático. Estas transformaciones afectaron a las actividades económicas agrícolas debido al proceso de cambio generado por el fin de la Pequeña Edad de Hielo y el inicio prematuro del calentamiento global en el siglo XVIII.

Pero las variaciones en las condiciones climáticas son las que generaron diversas alteraciones en la producción agropecuaria, el abastecimiento de alimentos, la infraestructura hidráulica, la organización de la producción, la aparición de epidemias, las alteraciones demográficas y los procesos migratorios, en especial en una ciudad como Lima, donde el principal abastecimiento de alimentos provenía de los valles de Lima (Pachacamac, Surco, Carabayllo, Late, Maranga, 
Callao y etc.) y de los circuitos comerciales, de estancias ganaderas y los flujos de fuerza laboral de los partidos de llanos y de sierra.

La falta de postores para los diversos arrendamientos que la ciudad ofrecía es un indicativo de los problemas que la variabilidad climática presentó durante los primeros años del siglo XVIII en la capital del virreinato del Perú. Es evidente que, para inicios de siglo, la falta de un postor idóneo para suministrar a Lima de ganado de Castilla se debió a que los criadores se encontraron incapacitados de criar ganado suficiente para el abasto de la ciudad. Esta incapacidad se produjo por la variabilidad climática durante todo el siglo XVIII, ya que en los años anteriores los arrendamientos habían logrado ser cubiertos por diversos criadores.

Por los mismos años podemos observar, en las fuentes documentales, que no solo el ganado de Castilla se vio afectado por los malos años, sino también la producción de vino y aguardiente. La quiebra de los arrendatarios del mojonazgo constituye un indicativo de los problemas por los que atravesaron los recaudadores de estos impuestos. Del mismo modo, la evidente falta de postores y las constantes rebajas en las obligaciones que estos arrendatarios tuvieron que pagar a los cabildos civil y eclesiástico ponen de manifiesto los problemas de variabilidad climática que Lima atravesó durante el siglo XVIII.

Todas esas alteraciones se presentaron como recurrentes y tuvieron características similares producto del ENSO, en un contexto climático de circulación océano atmosférico distinto al actual. Por eso, consideramos necesario su estudio sistemático a lo largo de nuestra historia a partir de varios marcadores climáticos, para reconocer su desenvolvimiento con las estructuras económicas, sociales, políticas y culturales que fueron afectadas de diferente manera e intensidad. El presente estudio tiene por ello la finalidad de establecer elementos teóricos y metodológicos que sostengan la articulación ambiental de la sociedad con modelos comparativos pertinentes para gestionar políticas públicas para el ordenamiento del territorio y la prevención ante los inevitables nuevos eventos catastróficos en el futuro.

\section{Bibliografía}

Barriendos, Mariano (2005). "Variabilidad climática y riesgos climáticos en perspectiva histórica. El caso de Catalunya en los siglos XVIII - XIX", Revista de Historia Moderna, (23): 11-34.

Barriendos, Mariano (1999). “Climatología histórica. Fuentes y métodos”, Recuperado de http://www.meteosort. com/meteosort/cas/q_d_38.htm.

Barriendos, Mariano y Javier Vide (1995). "The use of rogation ceremony record in climatic reconstruction: a case study from Catalonia (Spain)”. Climatic Change, (30): 201-221.

Bell, Martha (2013). The governance of food technology and environmental resource flows: connecting mills, water, wheat, and people in colonial Lima, Peru (1535-1700) (tesis de doctorado en Geografia). Universidad del Estado de Pensilvania, Estados Unidos.

Camuffo, Dario, Chiara Bertolin, Patrizia Schenal, Alberto Craievich y Rossella Granziero (2014) "The Litle Ice Age in Italy from documentary proxies and early instrumental records”. Mediterraneé, (122): 17-30.

Carcelén Reluz, Carlos (2007). “Idolatría indígena y devoción criolla como respuestas a la variabilidad climática en lima y Huarochirí durante el siglo XVIII”. Investigaciones Sociales, (11): 173 - 188.

Carcelén Reluz, Carlos (2009). "Historia del Clima y el medio ambiente en Lima y el Perú Central, en el siglo XVIII: Problema de investigación y fuentes históricas”. Revista de Historia de América, (140): 51-94.

Carcelén Reluz, Carlos (2011). “La visión ilustrada de los desastres en lima durante el siglo XVIII”. Cuadernos de Geografía, 20 (1): 55-64.

Caviedes, Cesar (2001). El Nino in history: Storming through the ages. Gainesville: University Press of Florida.

De Fina, Armando y Andrés Ravello (1973). Climatología y fenología agrícolas. Buenos Aires: Eudeba. 
Febres Villarroel, Oscar (1964). “La crisis agrícola del Perú en el último tercio del siglo XVIII”. Revista Histórica, (27): 102-109.

Flores Galingo, Alberto (1991). La ciudad sumergida: Aristocracia y plebe en Lima 1760-1830. Lima: Editorial Horizonte.

Garza Merodio, Gustavo (2014). “Características de la Pequeña Edad de Hielo en el México central a través de fuentes documentales”. Investigaciones Geográficas, (85): 82-94.

Gentile Lafaille, Margarita (1976). Los Yauyos de Chaclla. Del siglo XV al XVIII (tesis de bachillerato en Ciencias Sociales). Universidad Nacional Mayor de San Marcos, Lima, Perú.

Gergis, Joelle y Anthony Fowler (2008). "A history of ENSO events since A.D 1525: Implications for future climate change". Climate change, 92 (3): 343-387.

Grove, Richard (2018). The Niño chronology and the Litle Ice Age. En Grove, Richard y George Adamson. The Niño in world history (pp. 49-79). London: Palgrave Macmillan.

Gúzman, Gloria, Guiomar Carranza, Eduardo Aguilera, David Soto, Juan Infante, Manuel Molina y Roberto García (2016). Cuestionando la narrativa historiográfica dominante sobre la baja productividad de las variedades tradicionales. Primeros resultados de un estudio de Historia Agraria Experimental. XV Congreso de Historia Agraria de la SEHA: 1-9.

Hocqueghem, Anne Marie (1992). "Los eventos el Niño y lluvias anormales en la costa del Perú: siglos XVI-XIX”. Boletín del Instituto de Estudios Andinos, 21 (1): 197 -278.

Huertas, Lorenzo. (2009). Injurias del tiempo. Desastres naturales en la historia del Perú. Lima: Editorial Universitaria.

Luterbacher, Jürg, Ralph Rickli, Elena Xoplaki, C. Tinguely, Christoph Beck, Christian Pfister y Heinz Wanner (2001). "The late maunder minimum (1675-1715) - A key period for studying decadal scale climatic change in Europe". Climatic Change, (49): 441-469.

Nieto, Mauricio, Paola Castaño y Diana Ojeda (2005). “"El influjo del clima sobre los seres organizados’ y la retórica ilustrada en el Seminario del Nuevo Reyno de Granada”. Historia Crítica, (30): 91-114.

Peralta, Pedro (1721-1747). El Conocimiento de los Tiempos. Lima: s/e.

Polo, Toribio (1913). Apuntes para una historia de las epidemias. Lima: Imprenta N. de Federico Barrionuevo.

Prieto, María del Rosario y Roberto Herrera (2001). "De sequías, hambrunas, plagas y 'otras varias y continuas calamidades acaecidas en la Jurisdicción de Córdoba durante el siglo XVIII”. Cuadernos de Historia, (4): $131-158$.

Rabatel, Antoine, Vincent Jomelli, Philippe Naveau, Bernard Francou y Delphine Grancher. (2005). Dating of Litle Ice Age glacier fluctuations in the tropical Andes: Charquini glaciers, Bolivia, $16^{\circ} \mathrm{S}^{\prime}$. Comptes Rendus Geoscience, 337: 1311-1322.

Rosi y Rubí, José (17 de febrero de 1791). “Razones físicas, que reprueban la costumbre de enterrar en las Iglesias”. Mercurio Peruano (tomo 1, número 14) (fols. 124-131). Lima: Imprenta Real de los Niños Expósitos.

Romero, Francisco (1791-1794). “Observaciones Meteorológicas”. Mercurio Peruano, Lima.

Ulloa, Antonio y Jorge Juan (1748). Observaciones astronómicas y físicas hechas por orden de S. M. en los reinos del Perú... de los cuales se deduce la figura y magnitud de la Tierra. Madrid: Por Juan de Zúñiga.

Unanue, Hipólito (1806) Observaciones sobre el clima de Lima y sus influencias en los seres organizados en especial el hombre. Lima: Imprenta Real de los Niños Huérfanos.

Vargas Ugarte, Rubén (1956). Historia del Perú. Virreinato (Siglo XVIII) 1700-1790. Lima: Librería Imprenta Gil.

Vargas Ugarte, Rubén (1966). Historia General del Perú, tomo IV. Lima: Editorial Carlos Milla Batres.

Villalba, Ricardo (1994). "Fluctuaciones climáticas en latitudes medias de América del Sur durante los últimos 1000 años: sus relaciones con la Oscilación del sur”. Revista Chilena de Historia Natural, (67): 453-461.

\section{Archivos consultados}

Archivo Histórico de la Municipalidad de Lima (AHML) 
Archivo del Arzobispado de Lima (AAL)

Archivo del Cabildo Metropolitano de Lima (ACML)

Biblioteca Nacional del Perú (BNP)

Presentado: 7 mayo 2019

Aceptado: 3 octubre 2019

Publicado online: 15 julio 2020 